\title{
Metabolic compensation of the Neurospora clock by a glucose-dependent feedback of the circadian repressor CSP1 on the core oscillator
}

\author{
Gencer Sancar, Cigdem Sancar, and Michael Brunner ${ }^{1}$ \\ Biochemistry Center, University of Heidelberg, D-69120 Heidelberg, Germany
}

Conidial separation 1 (CSP1) is a global transcription repressor. It is expressed under control of the white collar complex (WCC), the core transcription factor of the circadian clock of Neurospora. Here we report that the length of the circadian period decreases with increasing glucose concentrations in $\operatorname{csp} 1$ mutant strains, while the period is compensated for changes in glucose concentration in wild-type strains. Glucose stimulated CSP1 expression. Overexpression of CSP1 caused period lengthening and, eventually, complete dampening of the clock rhythm. We show that CSP1 inhibits expression of the WHITE COLLAR 1 (WC1) subunit of the WCC by repressing the wc1 promoter. Glucose-dependent repression of wc1 transcription by CSP1 compensated for the enhanced translation of WC1 at high glucose levels, resulting in glucose-independent expression of the WCC and, hence, metabolic compensation that maintained a constant circadian period. Thus, the negative feedback of CSP1 on WC1 expression constitutes a molecular pathway that coordinates energy metabolism and the circadian clock.

[Keywords: circadian clock; metabolism; glucose compensation; feedback loop; Neurospora]

Supplemental material is available for this article.

Received June 27, 2012; revised version accepted September 4, 2012.

Circadian clocks are self-sustained molecular oscillators that are based on interconnected transcriptional and posttranscriptional feedback loops. They coordinate the rhythmic expression of a large number of genes in anticipation of environmental perturbations associated with the daynight cycle of the earth (Dibner et al. 2010; Diernfellner and Schafmeier 2011; Hogenesch and Ueda 2011; Lowrey and Takahashi 2011). A major function of circadian clocks is to regulate metabolic processes to establish cellular homeostasis in a rhythmic environment /Gatfield and Schibler 2008; Duez and Staels 2009; Asher and Schibler 2011; Bray and Young 2011; Huang et al. 2011; SassoneCorsi 2012; Stratmann and Schibler 2012).

In mammals, the core circadian transcription factor CLOCK/BMAL1 activates expression of the Period (Per) and Cryptochrome (Cry) genes, and the PER and CRY proteins rhythmically repress CLOCK/BMAL1 in a negative feedback loop (Takahashi et al. 2008). In a second loop, CLOCK/BMAL1 activates the Rev-erb and Ror nuclear receptors genes (Preitner et al. 2002), which encode repressors and activators, respectively, that control rhythmic expression of Bmal1 and probably also the Clock, Per,

${ }^{1}$ Corresponding author

E-mail michael.brunner@bzh.uni-heidelberg.de

Article is online at http://www.genesdev.org/cgi/doi/10.1101/gad.199547.112. and Cry genes (Preitner et al. 2002; Liu et al. 2007; Bugge et al. 2012; Cho et al. 2012). Although rhythmic expression of BMAL1 is not required for the function of the clock, hepatic double deletion of the genes for the partially redundant repressors, Rev-erb- $\alpha$ and Rev-erb- $\beta$, causes arrhythmicity in mouse livers (Bass 2012; Cho et al. 2012; Stratmann and Schibler 2012). The Rev-erb nuclear receptors control the expression of many genes involved in the metabolism of lipids and glucose and thus allow the clock to rhythmically regulate cellular metabolism. When Rev-erb function is compromised in the liver, animals develop metabolic syndrome and obesity /Gatfield and Schibler 2008; Duez and Staels 2009; Bass 2012; Bugge et al. 2012; Cho et al. 2012; Solt et al. 2012; Stratmann and Schibler 2012).

Metabolism, in turn, feeds back on the circadian clock via $\mathrm{NAD}^{+}$, a substrate of the histone deacetylase SIRT1, which is recruited by CLOCK/BMAL1 to circadian genes (Nakahata et al. 2008; Bellet et al. 2011). Additional signaling pathways likely exist, and the REV-ERBs are candidates for the cross-talk between metabolism and circadian clocks (Solt et al. 2012; Stratmann and Schibler 2012).

In Neurospora, the WHITE COLLAR 1 (WC1) and WC2 subunits form the heterodimeric white collar complex (WCC), which is the core transcription factor of the circadian clock (Crosthwaite et al. 1997; Dunlap and 
Loros 2004; Heintzen and Liu 2007). The WCC activates morning-specific expression of the circadian clock gene frequency $(f r q)$. WCl is a photoreceptor (Froehlich et al. 2002; He et al. 2002). In light-dark cycles, the WCC dimerizes (Malzahn et al. 2010) and activates expression of the photoreceptor gene vivid ( $v v d$ ) (Schwerdtfeger and Linden 2003; Zoltowski et al. 2007). FRQ and VVD inhibit the WCC in distinct negative feedback loops: FRQ forms a complex with CK1a and FRH (Gorl et al. 2001; Cheng et al. 2005) and inhibits the WCC by supporting its phosphorylation (Schafmeier et al. 2005). VVD inhibits the light-activated WCC (Chen et al. 2010) by disrupting WCC dimers (Malzahn et al. 2010). Many morningspecific genes are directly activated by the WCC (Chen et al. 2009; Smith et al. 2010).

We recently showed that the WCC-controlled gene conidial separation 1 (csp1) encodes a global circadian repressor that modulates expression of $\sim 800$ genes in Neurospora (Sancar et al. 2011). Many of these genes are rhythmically expressed with an evening-specific phase. Target genes of CSP1 are predominantly involved in metabolism of lipids and glucose in particular.

Here we report that glucose metabolism, in turn, has the potential to feed back on the core FRQ/WCC molecular oscillator via CSP1. CSP1 is a glucose-dependent repressor of $w c-1$ transcription. This negative feedback loop compensates the core oscillator against glucose and other carbon sources and thus coordinates cellular metabolism with the circadian clock.

\section{Results}

CSP1 is a circadian repressor with some similarities to the yeast transcription repressors NRG1 and NRG2 (Sancar et al. 2011). Since NRG1 and NRG2 are regulated by glucose (Kuchin et al. 2002; Berkey et al. 2004; Vyas et al. 2005), we asked whether CSP1 modulates the Neurospora circadian clock in response to glucose levels. To assess the period length of the clock, we analyzed the circadian conidiation rhythm of a csp1 mutant and a corresponding control strain (wild-type $b d$ ) in race tubes containing $0 \%, 0.1 \%, 0.3 \%$, and $0.5 \%$ glucose (Fig. $1 \mathrm{~A}$ ). We found that the period length of the csp1 mutant decreased with increasing concentrations of glucose $(0 \%$ glucose: $22.20 \pm 0.18 \mathrm{~h} ; 0.5 \%$ glucose: $19.90 \pm 0.10 \mathrm{~h}$ ) but that the period length of the $b d$ control strain was essentially independent of glucose concentration $(0 \%$ glucose: $22.45 \pm 0.15 \mathrm{~h} ; 0.5 \%$ glucose: $22.15 \pm 0.05 \mathrm{~h}$ ) (Fig. 1B). Similar results were obtained when fructose and sucrose were used as carbon sources (Supplemental Fig. S1A,B).

In addition, we generated a $\Delta \operatorname{csp} 1$ bd strain that expresses a luciferase reporter under the control of the frq promoter and followed its clock-controlled bioluminescence rhythm in constant darkness (Fig. 1C). At a low glucose level $(0.05 \%)$, the period length of $\Delta c s p 1$ frq-luc bd was $20.56 \pm 0.11 \mathrm{~h}(n=15)$, while it was $18.96 \pm 0.10 \mathrm{~h}(n=$ $12)$ at a high glucose level $(0.3 \%)$. The period length of the corresponding $b d$ frq-luc control strain (Gooch et al. 2008) was nearly unaffected by glucose (low glucose: $20.58 \pm$ $0.11 \mathrm{~h}$; high glucose: $20.35 \pm 0.03 \mathrm{~h}$ ). These results suggest

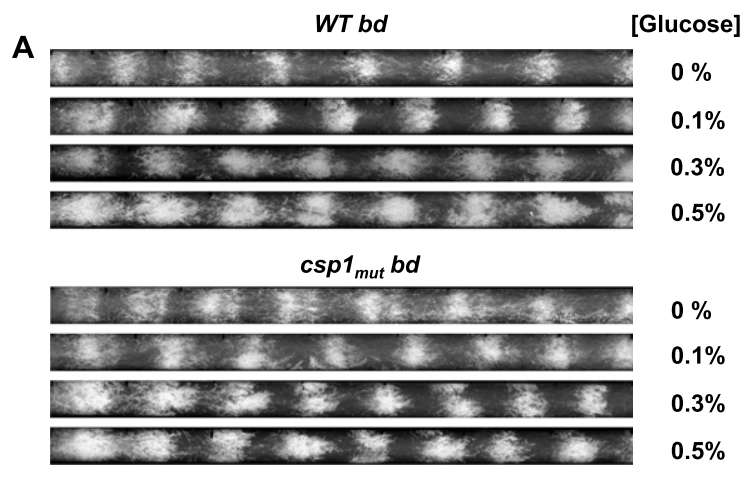

B
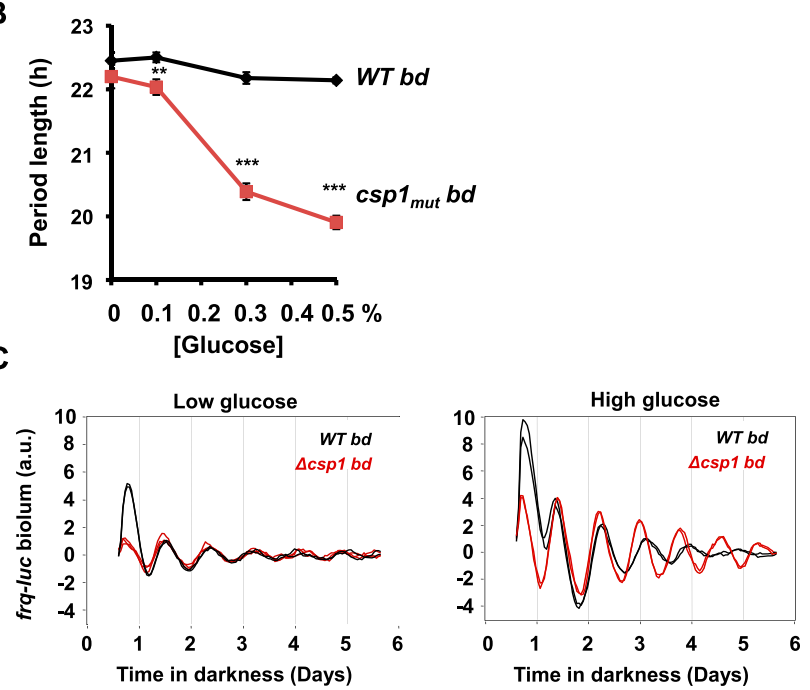

Figure 1. Glucose dependence of the period length of the csp1 mutant. (A) Representative race tube assays of the control (wildtype [WT] $b d)$ and a $c s p 1$ mutant $\left(c s p_{\text {mut }} b d\right)$ at different glucose concentrations. $(B)$ Graph showing the free-running period length of the strains analyzed in $A$. The period lengths of the $\operatorname{csp} 1$ mutant at different glucose concentrations were $22.20 \pm 0.18 \mathrm{~h}(n=13)$ at $0 \%$ glucose, $22.03 \pm 0.12 \mathrm{~h}(n=18)$ at $0.1 \%$ glucose, $20.38 \pm 0.13$ $(n=13)$ at $0.3 \%$ glucose, and $19.90 \pm 0.10 \mathrm{~h}(n=16)$ at $0.5 \%$ glucose. Error bar represents \pm SEM. $\left(^{\star \star}\right) P<0.01$; $\left(^{\star \star \star}\right) P<10^{-9}$. $(C)$ Representative traces of the frq-luc luciferase activity in wildtype $b d$ and $\Delta c s p 1$ bd (deletion of the csp1 ORF) backgrounds at low $(0.05 \%)$ and high $(0.3 \%)$ levels of glucose. The period lengths of $\Delta \operatorname{csp} 1 \mathrm{bd}$ were $20.56 \pm 0.11 \mathrm{~h}(n=15)$ at low glucose and $18.96 \pm$ $0.10 \mathrm{~h}(n=12)$ at high glucose. The period lengths of wild-type $b d$ were $20.58 \pm 0.11 \mathrm{~h}(n=15)$ at low glucose and $20.35 \pm 0.03$ $\mathrm{h}(n=13)$ at high glucose. The period lengths are given \pm SEM.

that CSP1 is required to compensate the circadian clock for changes in glucose concentration.

To determine how CSP1 levels affect the circadian clock, we generated a frq-luc reporter strain that expresses CSP1-R $1_{\text {Flag-His, }}$ a stable functional version of CSP1 (Sancar et al. 2011), under the control of the quinic acid (QA)inducible qa2 promoter. In the absence of $\mathrm{QA}$, the qa2$\operatorname{csp} 1-R 1_{\text {Flag-His }}$ strain displayed a robust conidiation rhythm on race tubes with a period of $22.18 \pm 0.07 \mathrm{~h}$. At $60 \mu \mathrm{M}$ QA, the period was $\sim 2.5 \mathrm{~h}$ longer $(24.52 \pm 0.45 \mathrm{~h})$, and at $6 \mathrm{mM} \mathrm{QA}$, the overt conidiation rhythm was lost (Fig. 2A, top panel). The conidiation rhythm of a corre- 
A

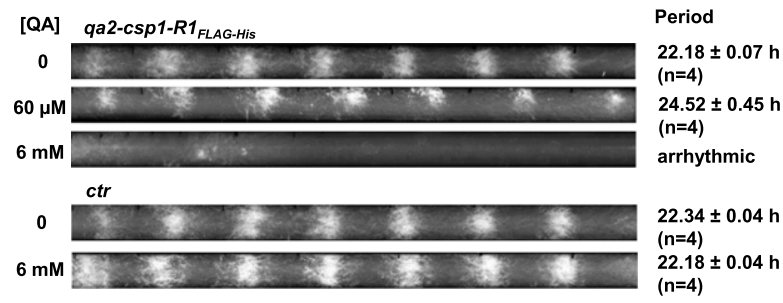

B

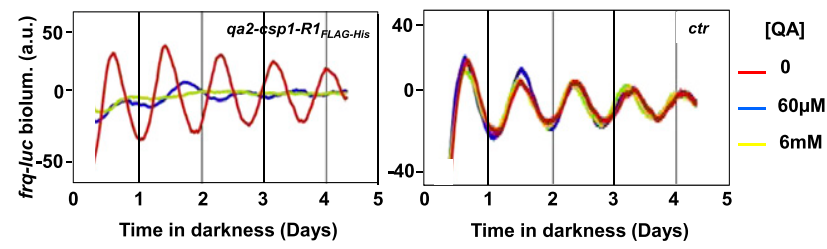

Figure 2. Overexpression of CSP1 inhibits the clock. $(A)$ Representative race tube assay of the qa2-csp1-R1 $1_{\text {Flag-His }}$ strain (top panel) and the control strain (ctr) (bottom panel) at different QA concentrations. The ctr strain expresses a frq-luc reporter and carries the $b d$ mutation. The qa2-csp1-R $1_{\text {Flag-His }}$ strain was generated by sitedirected knock-in of a QA-inducible and stable version of CSP1 into the $\operatorname{csp} 1$ locus of the ctr strain. The period lengths (in hours [h]) are indicated \pm SEM. (B) frq-luc luciferase activity in qa2-csp1-R1 $1_{\text {Flag-His }}$ and ctr at different QA concentrations ( \pm SEM). The periods of qa2$\operatorname{csp} 1-R 1_{\text {Flag-His }}$ were $20.42 \pm 0.11 \mathrm{~h}(n=8)$ in the absence of QA and $24.06 \pm 0.21 \mathrm{~h}(n=8)$ at $60 \mu \mathrm{M}$ QA. No rhythmic luciferase activity was identified at $6 \mathrm{mM}$ QA. The periods of the ctr strain were $20.80 \pm 0.12 \mathrm{~h}(n=8)$ without QA, $20.33 \pm 0.10 \mathrm{~h}(n=9)$ at $6 \mathrm{mM}$ QA, and $20.42 \pm 0.10 \mathrm{~h}(n=9)$ at $60 \mu \mathrm{M}$ QA.

sponding control strain was not affected by QA (Fig. 2A, bottom panel).

Similar results were obtained when we followed the molecular oscillation of the frq-luc gene (Fig. 2B). In the absence of QA, the qa2-csp1-R $1_{\text {Flag-His }}$ strain displayed a high-amplitude bioluminescence rhythm with a period of $20.42 \pm 0.11 \mathrm{~h}$. The rhythm was damped and the period was longer $(24.06 \pm 0.21 \mathrm{~h})$ at $60 \mu \mathrm{M}$ QA, and the bioluminescence rhythm was essentially lost at $6 \mathrm{mM}$ QA, while the bioluminescence rhythm of the control strain was not affected by QA.

The data indicate that CSP1, which is an output of the clock, directly or indirectly feeds back on the core circadian oscillator in a glucose-dependent manner.

Next, we analyzed the phase of the clock-controlled abundance and phosphorylation rhythm of FRQ in highglucose medium. When a wild-type strain was grown in a $12 \mathrm{~h}: 12 \mathrm{~h}$ light-dark (LD) cycle, the onset of FRQ synthesis was observed before the dark-light transition (Zeitgeber time [ZT] 24) (Supplemental Fig. S1C,D). Newly synthesized, hypophosphorylated FRQ accumulated later in $\operatorname{csp} 1-R 1_{\text {Flag-His }}$ and earlier in $\Delta \operatorname{csp} 1$, supporting that CSP1 affects the core oscillator of the circadian clock. The data indicate that CSP1 shifts the phase of the clock under entrained conditions.

Since CSP1 affects the circadian period and the phase of the clock at high but not low glucose levels, we analyzed its expression in response to glucose levels in a strain expressing $\operatorname{csp} 1_{\text {Flag-His }}$ under the control of the endogenous $\operatorname{csp} 1$ promoter (Sancar et al. 2011). Levels of $\operatorname{csp} 1_{\text {Flag-His }}$ RNA and CSP $1_{\text {Flag-His }}$ protein were higher in $2 \%$ than in $0.1 \%$ glucose (Fig. 3A,B). Moreover, addition of $2 \%$ glucose to $\operatorname{csp} 1_{\text {Flag-His }}$ grown in low glucose resulted in induction of $\operatorname{csp} 1_{\text {Flag-His }}$ RNA and protein (Fig. 3C,D). Even expression of the stable CSP1-R $1_{\text {Flag-His }}$ version under the control of the endogenous $\operatorname{csp} 1$ promoter was elevated at high glucose (Supplemental Fig. S2C). The data indicate that glucose regulates expression of $\operatorname{csp} 1$ on the level of transcription.

Similar results were obtained when the glucosedependent expression of nontagged CSP1 was analyzed in wild-type $b d$ and wild-type strains (Supplemental Fig. S2A,B). Notably, glucose-dependent expression of CSP1 was also observed in a $\Delta w c 2$ strain (Supplemental Fig. S2D), indicating that glucose-induced $\operatorname{csp} 1$ transcription is not dependent on the WCC. In addition to the glucose, expression of CSP1 $1_{\text {Flag-His }}$ was induced by adding fructose and sucrose to the medium (Supplemental Fig. S2E,F). This suggests that the availability of a carbon source is critical for CSP1 expression.

Analysis of our published CSP1 chromatin immunoprecipitation (ChIP) combined with deep sequencing (ChIPseq) (Sancar et al. 2011) data suggests that CSP1 binds to the wc1 promoter (Fig. 4A). ChIP of CSP1 from strains that express either functional CSP1 (csp $\left.1_{\text {Flag-His }}\right)$ or a DNAbinding mutant of CSP1 $\left(Z n_{\text {mut }} \operatorname{csp} 1_{\text {Flag-His }}\right)$ confirmed the binding of CSP1 to the wc1 promoter (Supplemental Fig. S3A). To assess the functional relevance of CSP1 binding to the $w c 1$ promoter, we measured $w c 1$ RNA and WC1 protein expression in wild-type, $\Delta \operatorname{csp} 1, \operatorname{csp} 1_{\text {Flag-His, }}$ and csp1-R1 $1_{\text {Flag-His }}$ strains (Fig. 4B,C). Wild type and $\operatorname{csp} 1_{\text {Flag-His }}$ expressed similar levels of $w c 1$ RNA and WC1 protein,
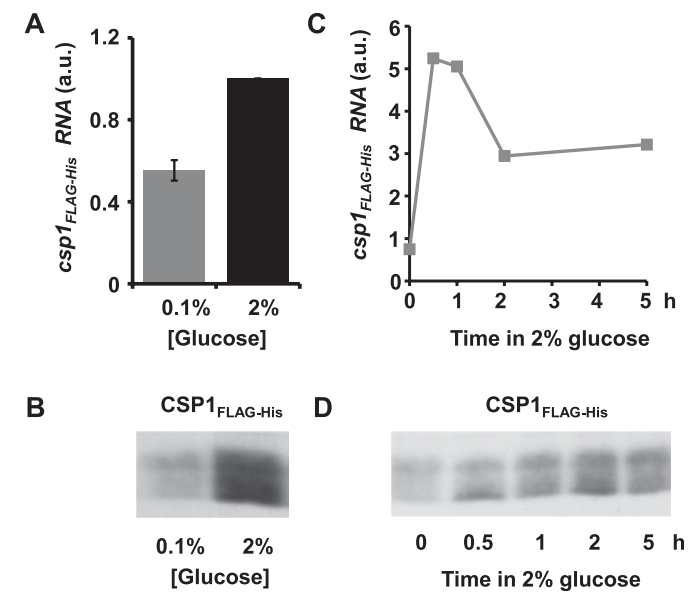

Figure 3. CSP1 expression is positively regulated by glucose. (A) $\operatorname{csp} 1_{\text {Flag-His }}$ RNA levels in low $(0.1 \%)$ and high $(2 \%)$ glucose $(n=3, \pm \mathrm{SD}) .(B)$ Western blot showing the $\mathrm{CSP} 1_{\text {Flag-His }}$ protein levels in low and high glucose. $(C) \operatorname{csp} 1_{\text {Flag-His }}$ RNA levels in cultures grown in $0.1 \%$ glucose after adding glucose to a final concentration of $2 \%$. The average of the two independent experiments is shown. $(D)$ Western blot with anti-Flag antibody showing CSP1 $1_{\text {Flag-His }}$ protein levels after glucose induction. 
A

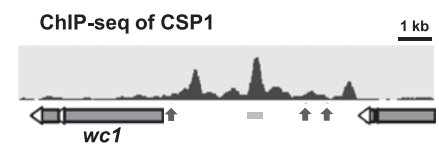

B

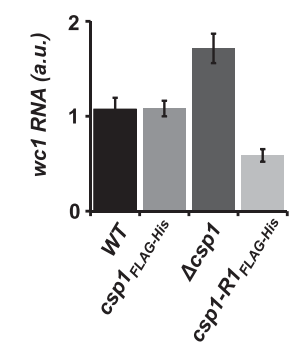

C

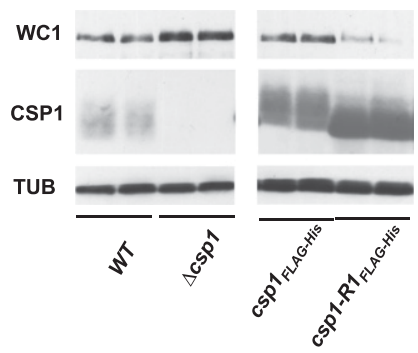

Figure 4. CSP1 regulates $w c 1$ expression by binding to the $w c 1$ promoter. $(A)$ ChIP-seq analysis of CSP1-binding sites of the wc1 promoter. Sequence reads are plotted above the genomic region of the wc1 locus. The arrows show the location of the WCCbinding sites (Smith et al. 2010). The bar indicates the region used to design the primers used for ChIP-PCR. $(B)$ RNA levels of wc1 in wild type (WT), $\Delta \operatorname{csp} 1, \operatorname{csp} 1_{\text {Flag-His, }}$ and $\operatorname{csp} 1-R 1_{\text {Flag-His }}$ were determined by qRT-PCR ( \pm SEM, $n=4)$. 28s rRNA was used for normalization. (C) Western blots showing WC1 and CSP1 levels of two independent experiments in wild type, $\Delta \operatorname{csp} 1, \operatorname{csp} 1_{\text {Flag-His }}$ and $\operatorname{csp} 1-R 1_{\text {Flag-His. }}$. Tubulin (TUB) was used as a loading control.

demonstrating that the epitope tagging did not compromise the function of CSP1. Levels of wc1 RNA and WC1 protein were elevated in $\Delta c s p 1$ and decreased in csp1$R 1_{\text {Flag-His }}$ strains, suggesting that CSP1 is a repressor of wC1 transcription. We then measured WC1 levels in the qa2-csp1-R $1_{\text {Flag-His }}$ strain. Induction of CSP1 $1_{\text {Flag-His }}$ expression by QA resulted in reduction of WC1 levels (Supplemental Fig. 3C). Furthermore, WC1 levels correlated inversely with the levels of CSP1-R $1_{\text {Flag-His }}$ in heteroplasmic transformants of $c s p 1-R 1_{\text {Flag-His }}$ that express different amounts of the repressor (Supplemental Fig. S3B). These results suggest that CSP1 inhibits WC1 expression in a negative feedback loop by repressing the wc1 promoter.

CSP1 modulates the expression of $\sim 800$ genes (Sancar et al. 2011). To determine whether binding of CSP1 to the wc1 promoter is sufficient for glucose compensation of the circadian clock, it would be ideal to eliminate the CSP1-binding sites. However, the wc1 promoter region contains 69 potential CSP1-binding sites and CSP1 binds over an extended region, which makes a mutagenesis approach unfeasible (Fig. 4A). We therefore exchanged the entire $w c 1$ promoter for the promoter of the nuclear pore complex gene nup98-96, which is not regulated by CSP1 (Sancar et al. 2011). Expression of WC1 was slightly less under the control of the nup98-96 than in a control strain, yet WC1 was functional and supported light-induced expression of target genes (Supplemental Fig. 4). The period length of the nup-wc1 strain decreased with increasing glucose concentration (Fig. 5) and displayed glucose dependence similar to the $\operatorname{csp} 1$ mutant strain. These data suggest that regulation of $w c 1$ transcription by CSP1 is a major pathway for glucose compensation of the clock.

Expression levels of WC1 determine the period length of the circadian clock (Cheng et al. 2001). We therefore analyzed how glucose-dependent regulation of wc1 by CSP1 affects Wc1 RNA and WC1 protein. At $0.1 \%$ glucose, when CSP1 is expressed at low levels, the levels of wc1 RNA were slightly higher $(\sim 1.4$-fold $)$ in $\Delta \operatorname{csp} 1$ than in wild type. At $2 \%$ glucose, wc1 RNA was less abundant in both strains relative to the ribosomal RNA that was used for normalization. However, wc1 RNA was $\sim 2.5$-fold more abundant in $\Delta \operatorname{csp} 1$ than in wild type, reflecting the glucose-dependent increase of CSP1 expression in wild type (Fig. 6A). Comparing the low- and high-glucose conditions suggests that CSP1 is a rather moderate transcription repressor under the conditions analyzed. We then analyzed WC1 protein (Fig. 6B). At $0.1 \%$ glucose, when CSP1 expression is low, WC1 levels were similar in wild type and $\Delta c s p 1$. At $2 \%$ glucose, when CSP1 expression is high, WC1 levels in wild type were similar to those

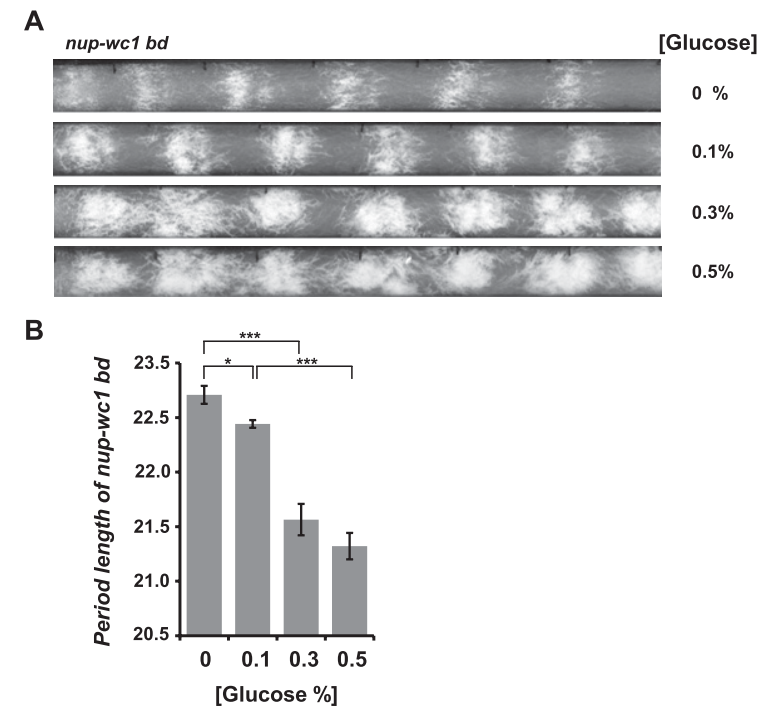

Figure 5. Expression of $w c 1$ by a CSP1-independent promoter results in loss of glucose compensation of the circadian clock. (A) The nup-98-96 promoter was cloned in front of the wc1 ORF and transformed into $\Delta w c 1 b d$. Representative race tube assay of the nup-wc1 bd at different glucose concentrations. (B) Graph showing the free-running period length of the nup-wc1 bd. The period lengths were $22.70 \pm 0.08 \mathrm{~h}(n=9)$ at $0 \%$ glucose, $22.44 \pm$ $0.03 \mathrm{~h}(n=9)$ at $0.1 \%$ glucose, $21.56 \pm 0.14(n=9)$ at $0.3 \%$ glucose, and $21.32 \pm 0.12 \mathrm{~h}(n=9)$ at $0.5 \%$ glucose. The period lengths are shown \pm SEM. $\left(^{\star}\right) P<0.05 ;\left(^{\star \star \star}\right) P<10^{-5}$. 


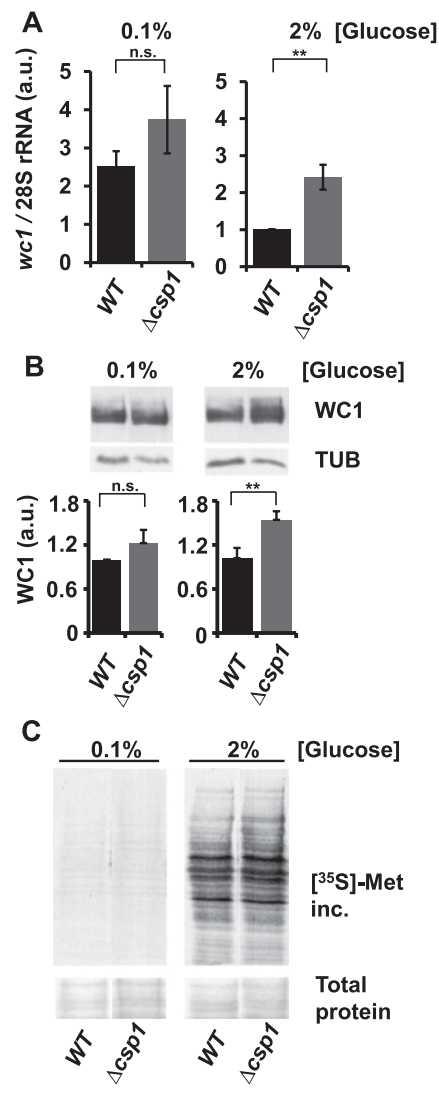

Figure 6. Increased translation rate at a high glucose level is compensated by CSP1-mediated repression of $W C 1$ transcription to keep WC1 levels independent of glucose. $(A)$ RNA levels of wc1 in wild type (WT) and $\Delta c s p 1$ at high and low glucose were determined by qRT-PCR ( \pm SEM, $n=4)$. 28 s rRNA was used for normalization. $\left.{ }^{* *}\right) P=0.013$. (B, top panel) Western blot showing WC1 levels in wild type and $\Delta \operatorname{csp} 1$ at $0.1 \%$ and $2 \%$ glucose. Tubulin was used as the loading control. The protein extraction was performed under denaturing conditions to prevent possible WC1 degradation in extracts of starved mycelia. (Bottom panel) Quantification of WC1 in wild type and $\Delta \operatorname{csp} 1$ at low and high glucose concentration $(n=5$, error bars represent \pm SEM). $\left(^{\star \star}\right) P<0.01 .(C)$ The incorporation of ${ }^{35}$ S-Met was analyzed to assess the general rate of protein synthesis of wild type and $\Delta \operatorname{csp} 1$ at $0.1 \%$ and $2 \%$ glucose.

at $0.1 \%$ glucose, while expression levels of WC1 were elevated about twofold in $\Delta \operatorname{csp} 1$ strains. The data suggest that CSP1 represses wc1 transcription in a glucose-dependent manner, which apparently results in glucosecompensated expression of WC1.

The availability of glucose (or another carbon source) as an energy source affects metabolism in a rather general manner (Schneper et al. 2004; Ferenci 2007; Boer et al. 2010). We therefore measured the rate of protein synthesis as a function of glucose. Incorporation of ${ }^{35} \mathrm{~S}$-Met was substantially higher at $2 \%$ than at $0.1 \%$ glucose in both wild type and $\Delta \operatorname{csp} 1$, suggesting a reduced translation rate in low glucose. The observations suggest that the CSP1dependent repression of wc1 RNA at high glucose levels counterbalances the enhanced general translation effi- ciency. Thus, the fine-tuned modulation of wc-1 transcription by CSP1 compensates the expression levels of $\mathrm{WC} 1$ against changes in glucose concentration.

\section{Discussion}

We show here that the Neurospora repressor CSP1 regulates transcription of $w c 1$ in response to glucose as well as fructose and sucrose. WC1 is the limiting subunit of the WCC, the core transcription activator of the circadian clock, and expression levels of the WCC determine the period length of the clock (Cheng et al. 2001). We show that glucose-dependent repression of wc-1 transcription by CSP1 compensates for enhanced translation of $\mathrm{WCl}$ at high levels of glucose, resulting in glucose-independent expression of the WCC (Fig. 7). Hence, CSP1 transduces information about the metabolic state of the cell to the core circadian oscillator

\section{$\Delta \operatorname{csp1}$}

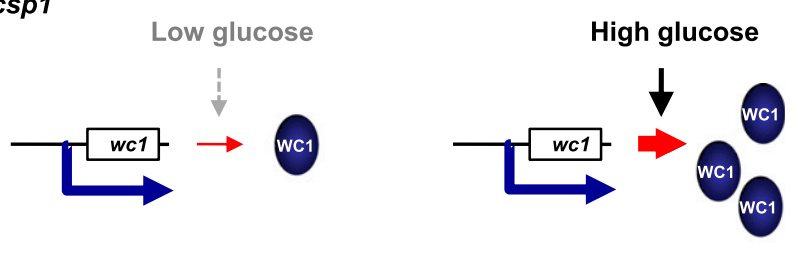

$W T$
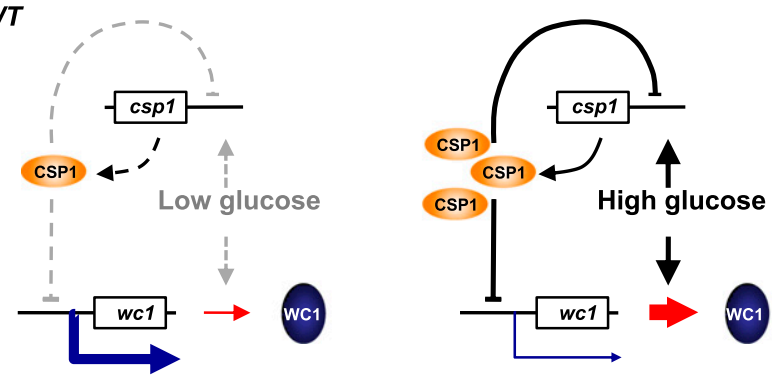

Figure 7. Model of glucose-compensated expression of WC1 mediated by CSP1. Expression levels of WC-1 affect the length of the circadian period. Glucose-dependent transcription of wc1 RNA and synthesis of WC1 protein in $\Delta c s p 1$ and wild type (WT) are schematically outlined. (Top panel) In $\Delta c s p 1$, transcription of $w c 1$ is not regulated, and wc1 RNA is efficiently produced at low and high glucose levels (thick blue arrows). Glucose affects the general translation rate. At low glucose, translation of wc1 RNA is rather inefficient (thin red arrow). The synthesis of WC1 protein per wc1 RNA is increased at high glucose (thick red arrow), and hence, WC1 accumulates at an elevated level. (Bottom panel) In wild type, CSP1 is a repressor of wc1 transcription. Transcription and thus expression of CSP1 are regulated by glucose. Overproduction of CSP1 is limited via a negative feedback of CSP1 on its own transcription. At low glucose, little CSP1 is synthesized, and repression of wc1 transcription is negligible. Hence, wc1 RNA is efficiently transcribed (thick blue arrow). Accumulation of CSP1 at high glucose leads to repression of wc1 transcription (thin blue arrow). The reduced transcription counterbalances the increased translation efficiency at high glucose (thick red arrow). Accordingly, WC1 levels are similar at low and high glucose. 
and compensates the circadian clock against glucoserelated changes of biochemical rates.

Metabolism enhances biochemical reaction rates, such as transcription and translation, in a rather general manner (Schneper et al. 2004; Ferenci 2007; Boer et al. 2010). Even moderate changes of expression rates could unbalance physiological processes and disturb cellular homeostasis. CSP1 is a global repressor that regulates $\sim 800$ genes in Neurospora (Sancar et al. 2011). It seems to compensate for the enhanced translation efficiency at elevated glucose (i.e., production of more polypeptides per RNA) on a global scale by reducing the rate of transcription of a large number of genes.

CSP1 is a short-lived protein $\left(t_{1 / 2} \approx 30 \mathrm{~min}\right)$ that is rapidly inactivated by phosphorylation and then degraded (Sancar et al. 2011). Its transcription is controlled in a light- and clock-dependent manner by the WCC and an unidentified transcription factor. Since the WCC is a morning-specific activator, the target genes of CSP1 are repressed in the (subjective) morning. Hence, genes that are transcribed under the control of a noncircadian activator and rhythmically repressed by CSP1 tend to peak in the (subjective) evening.

One of these genes is $w c 1$, and we show here that its transcription is repressed by CSP1 in a glucose-dependent manner. The transcription of $w c 1$ and $\operatorname{csp} 1$ is regulated in a similar fashion (Kaldi et al. 2006; Sancar et al. 2011), which is crucial for glucose compensation of the clock. Basic transcription of both genes is independent of the WCC, indicating that unidentified transcription factors control their expression. In addition, the WCC activates transcription of $\operatorname{csp} 1$ and $w c 1$ in a light-dependent manner. Regulation of $\operatorname{csp} 1$ and $w c 1$ by a constitutive and a rhythmic activator and by a rhythmic glucose-dependent repressor predicts that the circadian expression profile of these genes (i.e., amplitude and phase) should depend on the metabolic state (e.g., glucose concentration). Overexpression versus deletion of $\operatorname{csp} 1$ indicates that CSP1 is a strong transcription repressor that has the potential to regulate $w c-1$ expression over a broad range. Yet under supposedly physiological conditions $(0 \%-2 \%$ glucose $)$, the dynamic range of glucose-dependent regulation of wc1 transcription in wild-type strains is rather narrow ( $\sim 2.5$ times). This is due to a negative feedback loop of CSP1 on its own gene, which limits the WCC-dependent amplitude of the csp1 RNA and CSP1 protein rhythm. Although the range of $w c 1$ regulation is rather narrow, it covers the physiologically relevant conditions. We show that overexpression of CSP1 above physiological levels represses $w C 1$ to an extent that compromises the circadian clock so that the cells become arrhythmic.

Regulation of wc1 transcription by CSP1 displays a striking similarity to that of the mammalian Bmal1 gene by REV-ERB- $\alpha$ and its partially redundant homolog, REVERB- $\beta$ (Preitner et al. 2002; Liu et al. 2008; Cho et al. 2012). REV-ERB- $\alpha / \beta$ and CSP1 are global repressors that regulate a large number of genes involved in metabolism and link the circadian clock to energy homeostasis (Sancar et al. 2011; Bugge et al. 2012; Cho et al. 2012; Solt et al. 2012). REV-ERB- $\alpha$ affects in particular metab- olism of lipids and glucose in a circadian fashion (Raspe et al. 2002; Anzulovich et al. 2006; Yin et al. 2007; Duez et al. 2008; Le Martelot et al. 2009; Cho et al. 2012). Similarly, CSP1 controls rhythmic expression of genes involved in lipid and glucose metabolism (Sancar et al. 2011).

The circadian clocks of Neurospora and mammals are evolutionarily distant, and CSP1 and REV-ERB- $\alpha / \beta$ are not related by sequence. Yet both components have the potential to sense, directly or indirectly, metabolic signals and adjust the phase (or free-running period) of their circadian oscillators in response to the metabolic state of the organism. Thus, tight coupling of circadian oscillators with metabolism seems to be a central function of circadian clocks to coordinate metabolic processes and establish homeostasis in a rhythmic environment.

\section{Materials and methods}

\section{Neurospora strains and culture conditions}

Strains indicated with $b d$ carry the ras- $1^{b d}$ mutation (Belden et al. 2007) facilitating the detection of circadian conidiation rhythms on race tubes. Fungal Genetics Stock Center (FGSC) \#2489 was used as the wild-type strain. The csp1 mutant strain (FGSC \#2555) carries a Cys-to-Tyr exchange in the DNA-binding domain; hence, it is inactive (Lambreghts et al. 2009). The $b d$, his-3 strain was used for the transformation of frq-luciferase reporter constructs. The strain $\Delta \operatorname{csp} 1$ (FGSC \#11348) was generously crossed to his-3 by Deborah Bell-Pedersen's group for transformation of the frq-luciferase reporter (Gooch et al. 2008). $\Delta w c 1$ bd his-3 (FGSC \#9001) was used to generate nupwc1 bd. qa2-csp1-R1 $1_{\text {Flag-His }}$ was generated by knock-in of a QAinducible and stable version of CSP1 to the frq-luc reporter expression wild-type $b d$ strain. Standard growth medium contained $2 \%$ glucose, $0.5 \%$ L-arginine, $1 \times$ Vogel's medium, and $10^{2}$ $\mathrm{ng} / \mathrm{mL}$ biotin. In the experiments where different carbon sources and amounts were used, strains were grown in petri plates with $20 \mathrm{~mL}$ of standard medium with the indicated carbons source until mycelial mats formed. Mycelial pads $(1 \mathrm{~cm})$ were cut out and grown for $1 \mathrm{~d}$ in 100-mL flasks with $50 \mathrm{~mL}$ of Vogel's medium with the indicated carbon $\left(120 \mathrm{rpm}\right.$ at $\left.25^{\circ} \mathrm{C}\right)$. No additional carbon source was added to race tubes with QA.

\section{Protein analysis}

Neurospora protein extraction was performed as described (Schafmeier et al. 2006). Protein concentration was estimated by measuring absorption at $280 \mathrm{~nm}$ (NanoDrop, PeqLab). Western blotting was performed as described (Gorl et al. 2001). Nitrocellulose filters were stained with Ponceau $S$ to control uniform loading of the gels. Enhanced chemiluminescence signals were detected with X-ray films. For denaturing extracts, peqGOLD TriFAST reagent (PeqLab) was used following the manufacturer's protocol. To assess the translation rate at low glucose $(0.1 \%)$ and high glucose $(2 \%)$, mycelial discs were labeled with ${ }^{35}$ S-Met $(3.3 \mu \mathrm{Ci} / \mathrm{mL}, 3.3 \mathrm{pM})$ for $15 \mathrm{~min}$ in $30 \mathrm{~mL}$ of Vogel's medium. Labeling was terminated by adding $3.3 \mathrm{nM}$ nonradioactive methionine.

\section{RNA analysis}

RNA was prepared with peqGOLD TriFAST (PeqLab). The reverse transcription was done with the QuantiTect reverse 
transcription kit (Qiagen) following the manufacturer's instructions. Transcript levels were analyzed by quantitative real-time PCR in 96-well plates with the StepOnePlus real-time PCR system (Applied Biosystems). TaqMan Gene Expression Master Mix (Applied Biosystems), TaqMan, and UPL probes (Roche) were used. Primers and probes are listed in Supplemental Table S1.

\section{Generation of knock-in cassettes and Neurospora} transformations

The yeast in vivo recombination system (Colot et al. 2006) was used to generate $q a 2-\operatorname{csp} 1-R 1_{\text {Flag-His }}$. The $5^{\prime}$ region of $\operatorname{csp} 1$, the $q a$ promoter, and a previously generated $\operatorname{csp} 1-R 1_{\text {Flag-His }}$ knock-in cassette fragment (Sancar et al. 2011) were amplified with the primers listed in Supplemental Table S1. Transformation of Neurospora was performed as described (Colot et al. 2006).

\section{Tandem ChIP}

Nuclear extracts of $\operatorname{csp} 1_{\text {Flag-His }}$ and $\mathrm{Zn}_{\text {mut }} \operatorname{csp} 1_{\text {Flag-His }}$ were subjected to tandem ChIP with Ni-NTA enrichment, followed by anti-Flag immunoprecipitation as described (Sancar et al. 2011). Primers and probes used for the ChIP-PCR are listed in Supplemental Table 1.

\section{Real-time luciferase measurements}

Luciferase reporter assays were carried out as described (Sancar et al. 2011). We used $0.3 \%$ glucose as the carbon source where high-glucose conditions were used.

\section{Acknowledgments}

We thank Deborah Bell-Pedersen for Neurospora strains, Rüstem Yilmaz for technical help, and Axel Diernfellner for discussion. The work was supported by DFG grants BR 1375-1 and SFB 638. M.B. is a member of CellNetworks.

\section{References}

Anzulovich A, Mir A, Brewer M, Ferreyra G, Vinson C, Baler R. 2006. Elovl3: A model gene to dissect homeostatic links between the circadian clock and nutritional status. I Lipid Res 47: 2690-2700.

Asher G, Schibler U. 2011. Crosstalk between components of circadian and metabolic cycles in mammals. Cell Metab 13: 125-137.

Bass J. 2012. Drug discovery: Time in a bottle. Nature 485: 4546.

Belden WJ, Larrondo LF, Froehlich AC, Shi M, Chen CH, Loros JJ, Dunlap JC. 2007. The band mutation in Neurospora crassa is a dominant allele of ras-1 implicating RAS signaling in circadian output. Genes Dev 21: 1494-1505.

Bellet MM, Orozco-Solis R, Sahar S, Eckel-Mahan K, SassoneCorsi P. 2011. The time of metabolism: NAD ${ }^{+}$, SIRT1, and the circadian clock. Cold Spring Harb Symp Quant Biol 76: 31-38.

Berkey CD, Vyas VK, Carlson M. 2004. Nrg1 and nrg2 transcriptional repressors are differently regulated in response to carbon source. Eukaryot Cell 3: 311-317.

Boer VM, Crutchfield CA, Bradley PH, Botstein D, Rabinowitz JD. 2010. Growth-limiting intracellular metabolites in yeast growing under diverse nutrient limitations. Mol Biol Cell 21: 198-211.

Bray MS, Young ME. 2011. Regulation of fatty acid metabolism by cell autonomous circadian clocks: Time to fatten up on information? J Biol Chem 286: 11883-11889.
Bugge A, Feng D, Everett LJ, Briggs ER, Mullican SE, Wang F, Jager J, Lazar MA. 2012. Rev-erb $\alpha$ and Rev-erb $\beta$ coordinately protect the circadian clock and normal metabolic function. Genes Dev 26: 657-667.

Chen CH, Ringelberg CS, Gross RH, Dunlap JC, Loros JJ. 2009. Genome-wide analysis of light-inducible responses reveals hierarchical light signalling in Neurospora. EMBO I 28: 1029-1042.

Chen CH, DeMay BS, Gladfelter AS, Dunlap JC, Loros JJ. 2010. Physical interaction between VIVID and white collar complex regulates photoadaptation in Neurospora. Proc Natl Acad Sci 107: 16715-16720.

Cheng P, Yang Y, Liu Y. 2001. Interlocked feedback loops contribute to the robustness of the Neurospora circadian clock. Proc Natl Acad Sci 98: 7408-7413.

Cheng P, He Q, Wang L, Liu Y. 2005. Regulation of the Neurospora circadian clock by an RNA helicase. Genes Dev 19: 234-241.

Cho H, Zhao X, Hatori M, Yu RT, Barish GD, Lam MT, Chong LW, DiTacchio L, Atkins AR, Glass CK, et al. 2012. Regulation of circadian behaviour and metabolism by REV-ERB- $\alpha$ and REV-ERB- $\beta$. Nature 485: 123-127.

Colot HV, Park G, Turner GE, Ringelberg C, Crew CM, Litvinkova L, Weiss RL, Borkovich KA, Dunlap JC. 2006. A high-throughput gene knockout procedure for Neurospora reveals functions for multiple transcription factors. Proc Natl Acad Sci 103: 10352-10357.

Crosthwaite SK, Dunlap JC, Loros JJ. 1997. Neurospora wc-1 and wc-2: Transcription, photoresponses, and the origins of circadian rhythmicity. Science 276: 763-769.

Dibner C, Schibler U, Albrecht U. 2010. The mammalian circadian timing system: Organization and coordination of central and peripheral clocks. Annu Rev Physiol 72: 517549 .

Diernfellner AC, Schafmeier T. 2011. Phosphorylations: Making the Neurospora crassa circadian clock tick. FEBS Lett 585: 1461-1466.

Duez H, Staels B. 2009. Rev-erb- $\alpha$ : An integrator of circadian rhythms and metabolism. J Appl Physiol 107: 1972-1980.

Duez H, van der Veen JN, Duhem C, Pourcet B, Touvier T, Fontaine C, Derudas B, Bauge E, Havinga R, Bloks VW, et al. 2008. Regulation of bile acid synthesis by the nuclear receptor Rev-erbo. Gastroenterology 135: 689-698.

Dunlap JC, Loros JJ. 2004. The Neurospora circadian system. I Biol Rhythms 19: 414-424.

Ferenci T. 2007. Sensing nutrient levels in bacteria. Nat Chem Biol 3: 607-608.

Froehlich AC, Liu Y, Loros JJ, Dunlap JC. 2002. White Collar-1, a circadian blue light photoreceptor, binding to the frequency promoter. Science 297: 815-819.

Gatfield D, Schibler U. 2008. Circadian glucose homeostasis requires compensatory interference between brain and liver clocks. Proc Natl Acad Sci 105: 14753-14754.

Gooch VD, Mehra A, Larrondo LF, Fox J, Touroutoutoudis M, Loros JJ, Dunlap JC. 2008. Fully codon-optimized luciferase uncovers novel temperature characteristics of the Neurospora clock. Eukaryot Cell 7: 28-37.

Gorl M, Merrow M, Huttner B, Johnson J, Roenneberg T, Brunner M. 2001. A PEST-like element in FREQUENCY determines the length of the circadian period in Neurospora crassa. EMBO I 20: 7074-7084.

He Q, Cheng P, Yang Y, Wang L, Gardner KH, Liu Y. 2002. White collar-1, a DNA binding transcription factor and a light sensor. Science 297: 840-843.

Heintzen C, Liu Y. 2007. The Neurospora crassa circadian clock. Adv Genet 58: 25-66. 
Hogenesch JB, Ueda HR. 2011. Understanding systems-level properties: Timely stories from the study of clocks. Nat Rev Genet 12: 407-416.

Huang W, Ramsey KM, Marcheva B, Bass J. 2011. Circadian rhythms, sleep, and metabolism. I Clin Invest 121: 21332141.

Kaldi K, Gonzalez BH, Brunner M. 2006. Transcriptional regulation of the Neurospora circadian clock gene wc-1 affects the phase of circadian output. EMBO Rep 7: 199-204.

Kuchin S, Vyas VK, Carlson M. 2002. Snf1 protein kinase and the repressors $\mathrm{Nrg} 1$ and $\mathrm{Nrg} 2$ regulate FLO11, haploid invasive growth, and diploid pseudohyphal differentiation. Mol Cell Biol 22: 3994-4000.

Lambreghts R, Shi M, Belden WJ, Decaprio D, Park D, Henn MR, Galagan JE, Basturkmen M, Birren BW, Sachs MS, et al. 2009. A high-density single nucleotide polymorphism map for Neurospora crassa. Genetics 181: 767-781.

Le Martelot G, Claudel T, Gatfield D, Schaad O, Kornmann B, Sasso GL, Moschetta A, Schibler U. 2009. REV-ERB $\alpha$ participates in circadian SREBP signaling and bile acid homeostasis. PLoS Biol 7: e1000181. doi: 10.1371/journal.pbio. 1000181.

Liu AC, Welsh DK, Ko CH, Tran HG, Zhang EE, Priest AA, Buhr ED, Singer O, Meeker K, Verma IM, et al. 2007. Intercellular coupling confers robustness against mutations in the SCN circadian clock network. Cell 129: 605-616.

Liu AC, Tran HG, Zhang EE, Priest AA, Welsh DK, Kay SA. 2008. Redundant function of REV-ERB $\alpha$ and $\beta$ and nonessential role for Bmall cycling in transcriptional regulation of intracellular circadian rhythms. PLoS Genet 4: e1000023. doi: 10.1371/journal.pgen.1000023.

Lowrey PL, Takahashi JS. 2011. Genetics of circadian rhythms in mammalian model organisms. Adv Genet 74: 175-230.

Malzahn E, Ciprianidis S, Kaldi K, Schafmeier T, Brunner M. 2010. Photoadaptation in Neurospora by competitive interaction of activating and inhibitory LOV domains. Cell 142: 762-772.

Nakahata Y, Kaluzova M, Grimaldi B, Sahar S, Hirayama J, Chen D, Guarente LP, Sassone-Corsi P. 2008. The NAD ${ }^{+}$ dependent deacetylase SIRT1 modulates CLOCK-mediated chromatin remodeling and circadian control. Cell 134: 329340.

Preitner N, Damiola F, Lopez-Molina L, Zakany J, Duboule D, Albrecht U, Schibler U. 2002. The orphan nuclear receptor REV-ERB $\alpha$ controls circadian transcription within the positive limb of the mammalian circadian oscillator. Cell 110: 251-260.

Raspe E, Duez H, Mansen A, Fontaine C, Fievet C, Fruchart JC, Vennstrom B, Staels B. 2002. Identification of Rev-erb $\alpha$ as a physiological repressor of apoC-III gene transcription. $I$ Lipid Res 43: 2172-2179.

Sancar G, Sancar C, Brugger B, Ha N, Sachsenheimer T, Gin E, Wdowik S, Lohmann I, Wieland F, Hofer T, et al. 2011. A global circadian repressor controls antiphasic expression of metabolic genes in Neurospora. Mol Cell 44: 687697.

Sassone-Corsi P. 2012. Minireview: $\mathrm{NAD}^{+}$, a circadian metabolite with an epigenetic twist. Endocrinology 153: 1-5.

Schafmeier T, Haase A, Kaldi K, Scholz J, Fuchs M, Brunner M. 2005. Transcriptional feedback of Neurospora circadian clock gene by phosphorylation-dependent inactivation of its transcription factor. Cell 122: 235-246.

Schafmeier T, Kaldi K, Diernfellner A, Mohr C, Brunner M. 2006. Phosphorylation-dependent maturation of Neurospora circadian clock protein from a nuclear repressor toward a cytoplasmic activator. Genes Dev 20: 297-306.
Schneper L, Duvel K, Broach JR. 2004. Sense and sensibility: Nutritional response and signal integration in yeast. Curr Opin Microbiol 7: 624-630.

Schwerdtfeger C, Linden H. 2003. VIVID is a flavoprotein and serves as a fungal blue light photoreceptor for photoadaptation. $E M B O ~ J ~ 22: ~ 4846-4855$.

Smith KM, Sancar G, Dekhang R, Sullivan CM, Li S, Tag AG, Sancar C, Bredeweg EL, Priest HD, McCormick RF, et al. 2010. Transcription factors in light and circadian clock signaling networks revealed by genome-wide mapping of direct targets for Neurospora white collar complex. Eukaryot Cell 9: 1549-1556.

Solt LA, Wang Y, Banerjee S, Hughes T, Kojetin DJ, Lundasen T, Shin Y, Liu J, Cameron MD, Noel R, et al. 2012. Regulation of circadian behaviour and metabolism by synthetic REVERB agonists. Nature 485: 62-68.

Stratmann M, Schibler U. 2012. REV-ERBs: More than the sum of the individual parts. Cell Metab 15: 791-793.

Takahashi JS, Hong HK, Ko CH, McDearmon EL. 2008. The genetics of mammalian circadian order and disorder: Implications for physiology and disease. Nat Rev Genet 9: 764775.

Vyas VK, Berkey CD, Miyao T, Carlson M. 2005. Repressors $\mathrm{Nrg} 1$ and Nrg2 regulate a set of stress-responsive genes in Saccharomyces cerevisiae. Eukaryot Cell 4: 1882-1891.

Yin L, Wu N, Curtin JC, Qatanani M, Szwergold NR, Reid RA, Waitt GM, Parks DJ, Pearce KH, Wisely GB, et al. 2007. Reverb $\alpha$, a heme sensor that coordinates metabolic and circadian pathways. Science 318: 1786-1789.

Zoltowski BD, Schwerdtfeger C, Widom J, Loros JJ, Bilwes AM, Dunlap JC, Crane BR. 2007. Conformational switching in the fungal light sensor Vivid. Science 316: 1054-1057. 


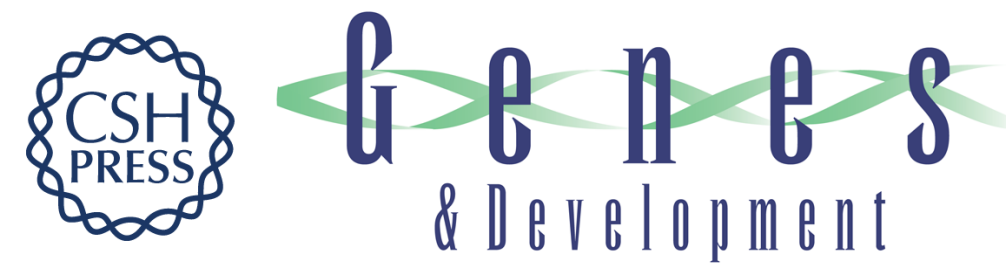

\section{Metabolic compensation of the Neurospora clock by a glucose-dependent feedback of the circadian repressor CSP1 on the core oscillator}

Gencer Sancar, Cigdem Sancar and Michael Brunner

Genes Dev. 2012, 26:

Access the most recent version at doi:10.1101/gad.199547.112

Supplemental http://genesdev.cshlp.org/content/suppl/2012/10/25/26.21.2435.DC1

Material

References This article cites 54 articles, 25 of which can be accessed free at:

http://genesdev.cshlp.org/content/26/21/2435.full.html\#ref-list-1

License

Email Alerting Receive free email alerts when new articles cite this article - sign up in the box at the top

Service right corner of the article or click here.

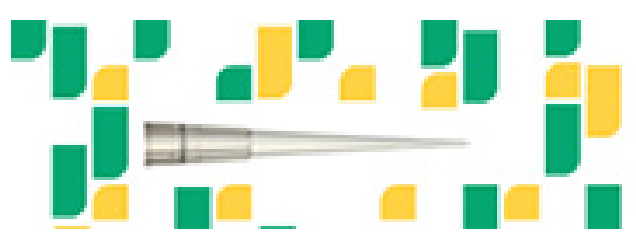

Focused on your science. 